\title{
Epicure: a European epidemiological study of patients with an advanced or metastatic Urothelial Carcinoma (UC) having progressed to a platinum-based chemotherapy
}

\author{
N. Houédé ${ }^{*}$, G. Locker ${ }^{2}$, C. Lucas ${ }^{3}$, H. Soto Parra ${ }^{4}$, U. Basso ${ }^{5}$, D. Spaeth ${ }^{6}$, R. Tambaro ${ }^{7}$, L. Basterretxea ${ }^{8}$, F. Morelli ${ }^{9}$,
} C. Theodore ${ }^{10}$, L. Lusuardi ${ }^{11}$, N. Lainez ${ }^{12}$, A. Guillot ${ }^{13}$, G. Tonini ${ }^{14}$, J. Bielle ${ }^{3}$ and X. Garcia Del Muro ${ }^{15}$

\begin{abstract}
Background: Platinum-based systemic chemotherapy is considered the backbone for management of advanced urothelial carcinomas. However there is a lack of real world data on the use of such chemotherapy regimens, on patient profiles and on management after treatment failure.

Methods: Fifty-one randomly selected physicians from 4 European countries registered 218 consecutive patients in progression or relapse following a first platinum-based chemotherapy. Patient characteristics, tumor history and treatment regimens, as well as the considerations of physicians on the management of urothelial carcinoma were recorded.
\end{abstract}

Results: A systemic platinum-based regimen had been administered as the initial chemotherapy in 216 patients: 15 in the neoadjuvant setting, 61 in adjuvant therapy conditions, 137 in first-line advanced setting and 3 in other conditions. Of these patients, 76 (35\%) were initially considered as cisplatin-unfit, mainly because of renal impairment (52 patients). After platinum failure, renal impairment was observed in $44 \%$ of patients, ECOG Performance Status $\geq 2$ in $17 \%$, hemoglobinemia $<10 \mathrm{~g} / \mathrm{dL}$ in $16 \%$, hepatic metastases in $13 \% .80 \%$ of these patients received further anticancer therapy. Immediately after failure of adjuvant/neoadjuvant chemotherapy, most subsequent anticancer treatments were chemotherapy doublets (35/58), whereas after therapy failure in the advanced setting most patients receiving further anticancer drugs were treated with a single agent (80/114). After first progression to chemotherapy, treatment decisions were mainly driven by Performance Status and prior response to chemotherapy ( $>30 \%$ patients). The most frequent all-settings second anticancer therapy regimen was vinflunine (70 \% of single-agent and $42 \%$ of all subsequent treatments), the main reasons evoked by physicians (>1 out of 4) being survival benefit, safety and phase III evidence.

Conclusion: In this daily practice experience, a majority of patients with urothelial carcinoma previously treated with a platinum-based therapy received a second chemotherapy regimen, most often a single agent after an initial chemotherapy in the advanced setting and preferably a cytotoxic combination after a neoadjuvant or adjuvant chemotherapy. Performance Status and prior response to chemotherapy were the main drivers of further treatment decisions.

Keywords: Urothelial carcinoma, Bladder cancer, Cisplatinum, Vinflunine, Epidemiology, Practice, Second-line, Metastatic

\footnotetext{
*Correspondence: nadine.houede@chu-nimes.fr

'Institut de Cancérologie du Gard - CHU Caremeau, 30029 Nîmes, Cedex 9,

France

Full list of author information is available at the end of the article
}

(c) 2016 The Author(s). Open Access This article is distributed under the terms of the Creative Commons Attribution 4.0 International License (http://creativecommons.org/licenses/by/4.0/), which permits unrestricted use, distribution, and reproduction in any medium, provided you give appropriate credit to the original author(s) and the source, provide a link to the Creative Commons license, and indicate if changes were made. The Creative Commons Public Domain Dedication waiver (http://creativecommons.org/publicdomain/zero/1.0/) applies to the data made available in this article, unless otherwise stated. 


\section{Background}

More than $90 \%$ of all cancers of the urinary tract are transitional cell carcinomas of the urothelium (urothelial carcinoma UC), $90 \%$ being localized in the bladder $[1,2]$. $\mathrm{UC}$ is a major health problem. In the European Union, bladder cancer is the fifth most frequently diagnosed malignant tumor with more than 124,000 new cases in 2012 corresponding to $4.7 \%$ of all human neoplasms. It accounts for about 41,000 deaths in Europe [3].

Those patients with muscle-invasive UC are at high risk of recurrence or progression, and half of them relapse after radical surgery. The majority of relapses are distant metastases and 10-15\% of patients are already metastatic at diagnosis [4]. Metastatic UC is an aggressive disease with a median survival not exceeding 6 months if untreated [5]. Chemotherapy plays an important role in the treatment of advanced stages of the disease. For first-line treatment of advanced or metastatic UC, a cisplatin-containing combination chemotherapy is considered the standard, either the classical MVAC (methotrexate, vinblastine, adriamycin, cisplatin) regimen or dose-dense MVAC and gemcitabine-cisplatin regimens which are better tolerated [6, 7]. The median survival is $13-15$ months with these regimens in the cisplatin-eligible patients $[2,6,8]$. However, up to $50 \%$ of patients are not eligible for a first-line cisplatincontaining chemotherapy because of their poor performance status (PS) and/or comorbidities. For these patients, there is no clear standard treatment but a carboplatin-based regimen or a single agent therapy are considered acceptable alternatives, according to European guidelines $[2,8,9]$.

A cisplatin-based neoadjuvant treatment is also recommended by clinical guidelines $[2,8,10]$ for some high-risk patients, before radical cystectomy. The role of adjuvant chemotherapy is more controversial but a meta-analysis of nine randomized trials and a large observational study suggested Disease-Free Survival and Overall Survival (OS) benefits for the patients who received cisplatin-based adjuvant chemotherapy [11, 12].

Second-line phase II data are highly variable with results depending on patient selection. Response rates for treatment of relapse with mono-chemotherapy are lower than those with combinations, but Progression-Free Survival and OS remain short with both options. In addition, prognostic factors in second-line were only recently established [13], making difficult the interpretation of oldest study results.

After platinum-based chemotherapy failure, the only chemotherapeutic agent approved in Europe is vinflunine. Some physicians also consider of re-challenging cisplatin-sensitive patients if progression occurs at least 6-12 months after first-line cisplatin-based combination. Both treatment modalities are endorsed by clinical guidelines (EAU, ESMO, ASCO) together with inclusion in clinical trials $[2,8,10]$.

Nevertheless, not all patients can benefit from secondline therapy after they have progressed to a first platinum-based chemotherapy. Probable reasons are the drug prescription limitations, impaired general health status that allows only best supportive care because of potential adverse effects. In some cases, non-approved drugs are used, based on physicians' experience.

Most UCs are diagnosed at the superficial stage and it is more complex to collect information on patients diagnosed with an advanced or metastatic stage, which explains why information on patient profiles and disease management is very limited at time of second systemic treatment.

After decades of unmet medical need with no strong evidence-based results and no specifically approved drug, physicians treatment decision may vary a lot. In addition there is no precise guidance according to the patient profile and prognostic factors.

Thus, there is a need to better characterize these patients and clarify physicians' practices. This could lead to optimizing the use of available treatments.

The objective of this non-interventional study is to define the characteristics of patients when progression (resistance or relapse) is demonstrated after a first systemic platinum-based treatment and to report the physician's therapeutic attitudes both in theory from physician's perspective and in daily practice according to the actual characteristics of patients attending a consultation during the survey period.

\section{Methods}

\section{Study design}

The study was a European ambispective survey reporting epidemiology and practices in the management of urothelial carcinoma (UC), following progression to a platinum-based chemotherapy given in adjuvant, neoadjuvant or metastatic settings.

The study aimed to draw an accurate picture of the current practices. So it was formally requested that usual medical practices should not be impacted by the study process.

A total sample of 280 patients was planned from approximately 70 centers selected at random and located in the participating countries: Austria, France, Italy and Spain.

The lists of centers in each country were established on the basis the centers had physicians experienced in the management of advanced or metastatic UC ( $\geq 6$ patients/year).

The random lists of centers took into account the private and public status of the institutions in accordance with each country mode of management for the disease at this stage. This led to a list of 171 physicians within the four participating countries. Sixty-one out of 70 planned 
centers finally participated due to 9 late cancellations, and 51 centers actively recruited patients (Fig. 1).

All patients signed a specific informed consent if requested or at least received detailed written information. In compliance with the regulations of each participating country, the study was approved by national authorities as a non-interventional study and assessed by ethics review boards of each participating institution, wherever applicable.

Two types of information were collected:

Firstly, real-life patient data from case report forms. Data were collected on the first series of consecutive patients seen on a visit, with an expected number of 4 to 8 patients per center, up to a maximum of 10 patients in a given center during the study period. Registered patients had to fit the inclusion criteria: age over 18 years, locally advanced or metastatic UC, pre-treatment with a platinum-based chemotherapy (regardless of its setting: neoadjuvant chemotherapy, adjuvant chemotherapy or palliative first-line in

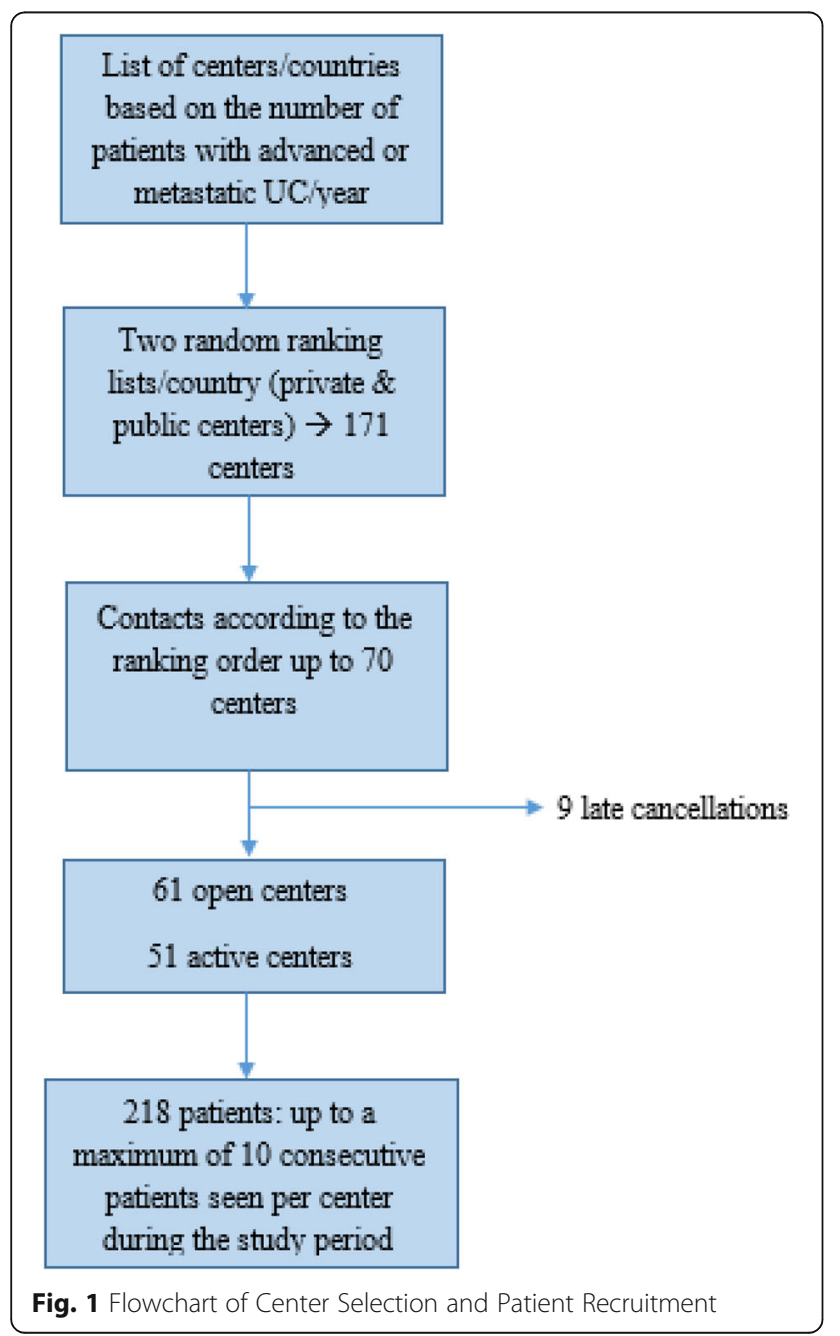

advanced/metastatic disease), having shown progression to the platinum-based treatment. Patients having received prior platinum-free systemic chemotherapy only were excluded.

Information collected included: initial patient characteristics and prior treatments, patient characteristics and comorbidities at the time of progression, disease management in the post-platinum setting.

Secondly, a questionnaire was filled by all participating physicians regarding their practices, at the time of patient inclusion. Physicians were asked how in theory he/she should manage the patient (anticancer treatment or alternatives) according to the patient characteristics after one systemic platinum-based chemotherapy regimen.

Statistics were mainly descriptive. Continuous data were summarized using the following items: frequency, median, range, mean, standard deviation and standard error if relevant. Categorical data were presented in contingency tables with frequencies and percentages of each modality (including missing data modality). $95 \%$ confidence intervals were calculated following the exact method. Furthermore, the relationship between the type of therapy (monochemotherapy or combination) received after progression and patient profiles after failure of first platinum treatment, was assessed by both univariate and multivariate analyses. In these exploratory analyses, a threshold of $p<0.05$ was considered for indicating a significant impact of patient characteristics.

\section{Results}

Two hundred and eighteen patients were included in the study by 51 active centers between April 2013 and April 2014. The recruited patients were 104 in Italy, 54 in Spain, 35 in France and 25 in Austria.

\section{Centers and patients characteristics}

The 51 active centers were located in Austria $(n=7)$, France $(n=7)$, Italy $(n=21)$ and Spain $(n=16)$. The split between public and private practice was $7 / 0$ in Austria, 6/1 in France, 16/5 in Italy and 15/1 in Spain. Among the 218 patients under study, 51 were followed in private centers, and 167 in public centers.

The mean number of patients recruited per center was 4.3 (between 1 and 10). Thirty-four centers recruited up to 4 patients, 11 centers between 5 and 9 patients, and 6 centers recruited 10 patients.

Of the 218 patients, 5 were excluded from the analysis because 2 did not received any platinum-based chemotherapy and 3 had multiple different consecutive chemotherapy regimens. However, these patients were included in the patient characteristics analysis. 
Males represented $84 \%$ of the patients and median age was 68 . Thirty-three patients $(15.1 \%)$ were $\geq 75$ years old. Regarding the number of systemic chemotherapy treatments at study entry, 45 patients $(21 \%)$ had received just one previous chemotherapy regimen; 136 (62\%) had received 2 regimens, and 37 (17\%) had received 3 or more regimens.

At registration, the treatment status of the patients was: ongoing chemotherapy $n=140$ (64 \%), best supportive care $n=42(19 \%)$, pending decision $n=28$ (13\%) and other situations (i.e. remission period, palliative surgery) $n=8$ (4\%).

Disease location at diagnosis was the bladder for 166 patients (76\%), upper urinary tract for 40 patients (18\%), and urethra or other/multiple locations for 12 patients $(6 \%)$. The stages at diagnosis comprised non muscle-invasive tumors for 24 patients $(11 \%)$, muscleinvasive for 62 patients $(28 \%)$ and locally advanced or metastatic disease for 132 patients $(61 \%)$. In this latter group, 49 patients $(22 \%)$ had distant metastases at diagnosis.

Most patients $(n=171-78 \%)$ were initially treated with surgery including radical cystectomy, partial cystectomy or nephro-ureterectomy. Only 8 patients (4\%) were treated by radiotherapy.

At the time of first platinum chemotherapy, $76 \mathrm{pa}-$ tients $(35 \%)$ were considered unfit for cisplatin, whereas 142 patients (65\%) were fit enough to receive a cisplatin-based chemotherapy. Table 1 displays the reasons for considering patients as unfit for cisplatin (some patients may have had several reasons).

As first systemic chemotherapy, 123 (56 \%) patients received a cisplatin-based regimen and 93 (43\%) patients a carboplatin-based regimen. Two patients were treated with a platinum-free regimen. Of the 213

Table 1 Conditions contributing to cisplatin ineligibility

\begin{tabular}{ll}
\hline Reason(s) for cisplatin-ineligibility $n=76$ & \\
\hline Single reason & $\mathbf{6 6}(\mathbf{8 7} \%)$ \\
Renal impairment only & $44(58 \%)$ \\
PS $\geq 2$ only & $9(12 \%)$ \\
Single reason not specified & $7(9 \%)$ \\
Heart failure only & $5(7 \%)$ \\
Hearing impairment only & $1(1 \%)$ \\
Multiple reasons & $10(\mathbf{1 3} \%)$ \\
PS $\geq 2+$ renal impairment & $5(7 \%)$ \\
PS $\geq 2+$ heart failure & $1(1 \%)$ \\
PS $\geq 2+$ other & $1(1 \%)$ \\
Renal impairment + Hearing impairment & $1(4 \%)$ \\
Renal impairment + other & $1(1 \%)$ \\
Renal impairment + Hearing impairment + other & $1(1 \%)$ \\
\hline
\end{tabular}

Other reasons included age or comorbidities patients who could be analyzed according to the setting of their first systemic chemotherapy regimen, 76 patients received their platinum therapy for neoadjuvant (15 patients) or adjuvant (61 patients) therapy objectives. Among them, approximately one third (26 patients) was treated with carboplatin and 50 patients with cisplatin. Regarding the remaining 137 patients who received firstline treatment for advanced disease, 66 were administered carboplatin and 71 cisplatin-based regimen. $45 \%$ of patients $(n=61)$ displayed objective response, of whom one third $(n=20)$ had complete response. $27 \%$ $(n=37)$ had disease stabilization and $26 \%(n=36)$ had progressive disease. At the time of subsequent postplatinum treatment decision, following treatment failure, many patients had poor general conditions (Table 2). Renal impairment was observed in $44 \%$ of patients, ECOG PS $\geq 2$ in $17 \%$, hemoglobinemia $<10 \mathrm{~g} / \mathrm{dl}$ in $16 \%$, hepatic metastases in $13 \%$.

Only $63(29 \%)$ patients were considered as not having any major constraint or co-morbid condition at the time of subsequent treatment decision.

Despite their condition, most of the patients $(n=175$ - $80 \%$ ) received further chemotherapy, 71 receiving combination therapy and 104 monotherapy. Only 18 patients $(8 \%)$ were managed by best supportive care. The remaining patients were waiting for treatment decisions or managed by other options. The chemotherapy regimens used after neoadjuvant/adjuvant platinum treatments were most often (60\%) a combination therapy, preferentially including a platinum agent. The main drug combined with platinum was gemcitabine. On the other hand, after platinum therapy given in the advanced setting, the majority of patients $(70 \%)$ were treated with

Table 2 Patient profile at time of post-platinum treatment decision

\begin{tabular}{lll}
\hline $\begin{array}{l}\text { Patient profile at time of post-platinum treatment } \\
\text { decision (number of available patients) }\end{array}$ & $N$ & $\%$ \\
\hline Age $(n=218)$ & 33 & 15 \\
$\quad \geq 75$ years & & \\
ECOG PS $(n=213)$ & $76 / 101$ & $36 / 47$ \\
$\quad$ PS $0 / 1$ & 36 & 17 \\
PS $\geq 2$ & & \\
Renal impairment $(n=217)$ & 95 & 44 \\
Creatinine clearance $<60 \mathrm{~mL} / \mathrm{min}$ & 25 & 12 \\
Creatinine clearance $<40 \mathrm{~mL} / \mathrm{min}$ & & \\
Low hemoglobin value $(n=217)$ & 35 & 16 \\
$\quad<10$ g/dL & 6 & 3 \\
Neutropenia (or leucopenia) $(n=217)$ & 28 & 13 \\
Hepatic metastases $(n=216)$ & 6 & 3 \\
Hepatic impairment $(n=217)$ & 13 & 6 \\
\hline Clinically relevant cardiac toxicity $(n=217)$ &
\end{tabular}


single-agent chemotherapy. Vinflunine represented $42 \%$ of all subsequent chemotherapy regimens and $70 \%$ of single agent therapy. Taxanes were the second type of chemotherapy used, representing $22 \%$ of single agent therapy with paclitaxel being used 3.6 times more often than docetaxel.

The different therapeutic options chosen are summarized in Table 3.

In the descriptive analysis, the main patient characteristics impacting the choice of any possible second-line treatment were performance status (50\%), response to previous chemotherapy (poor response: $33 \%$; good response: $22 \%$ ), age (23\%), renal impairment (23\%), multiple comorbidities $(7 \%)$ and visceral metastases $(7 \%)$.

Additional univariate and multivariate analyses looked into the association between patient characteristics at the time of progression to the first systemic chemotherapy and the subsequent treatment (single agent therapy or polychemotherapy regimen). The explored patient parameters were the established prognostic factors in second line (hemoglobinemia $<10 \mathrm{~g} / \mathrm{dL}$; ECOG PS; liver metastases) and other characteristics considered to potentially impact on treatment decision (age $<75$ or $\geq 75$; renal function - creatinine clearance below or over $60 \mathrm{~mL} / \mathrm{min}$; presence or not of cardiac toxicities; response to prior systemic chemotherapy; regimen of initial chemotherapy (cisplatin-based or not); number of cycles; reason of discontinuation of initial chemotherapy; time to progression after initial systemic chemotherapy and major toxicities during the course of prior cytotoxic regimen). In univariate analysis, 4 factors were significantly associated with either single agent or combination

Table 3 Disease management immediately following failure of the first platinum-based chemotherapy regimen

\begin{tabular}{|c|c|c|}
\hline $\begin{array}{l}\text { Initial platinum-based } \\
\text { chemotherapy } n,(\%)\end{array}$ & $\begin{array}{l}\text { Neo/adjuvant setting, } \\
n=76\end{array}$ & $\begin{array}{l}\text { Advanced setting, } \\
n=137\end{array}$ \\
\hline Cisplatin-based & $50(66 \%)$ & $71(52 \%)$ \\
\hline Carboplatin-based & $26(34 \%)$ & $66(48 \%)$ \\
\hline $\begin{array}{l}\text { Subsequent chemotherapy } \\
n,(\%)\end{array}$ & 58 (76 \%) & $114(83 \%)$ \\
\hline Single agent & 23 & 80 \\
\hline Vinflunine/Taxanes & $15 / 5$ & $57 / 18$ \\
\hline Gemcitabine/Other agent & $2 / 1$ & $2 / 3$ \\
\hline Combination therapy & 35 & 34 \\
\hline cisplatin-based & 11 & 5 \\
\hline carboplatin-based & 14 & 22 \\
\hline Other & 10 & 7 \\
\hline $\begin{array}{l}\text { Subsequent management by } \\
\text { BSC } n,(\%)\end{array}$ & 7 (9 \%) & $11(8 \%)$ \\
\hline $\begin{array}{l}\text { Pending decision or other }{ }^{a} \\
\mathrm{n},(\%)\end{array}$ & $11(14 \%)$ & 12 (9 \%) \\
\hline
\end{tabular}

therapy: hemoglobin level $(p=0.0034)$, response to initial chemotherapy $(p<0.0001)$, reason for discontinuation $(p=0.002)$ and time to progression $(p<0.0001)$. The multivariate analysis confirmed the association with response to previous chemotherapy $(p=0.0356)$ and time to progression $(p=0.0063)$, clearly impacting the choice of subsequent treatment; hemoglobin level was at the limit of significance $(p=0.0553)$.

\section{Usual practices for first systemic chemotherapy (according to physician's questionnaire)}

For the participating physicians $(n=51)$, the most commonly firstly used chemotherapy regimen is a doublet of platinum plus gemcitabine, whether patients are fit or not to receive cisplatin.

Tables 4 and 5 depict the preferred choices of physicians for first systemic chemotherapy, in patients fit and unfit for cisplatin, according to the setting (neoadjuvant-adjuvant or palliative for advanced or metastatic disease).

\section{Factors impacting treatment decisions following progression or relapse to a first platinum-based therapy (according to physician's questionnaire)}

Most physicians (42 out of 51, $82 \%$ ) declared that the way they would theoretically manage the disease after a progression or relapse does not really differ whether the first systemic chemotherapy was administered in the perioperative setting or as palliative first-line treatment.

The factors most impacting treatment decisions following progression or relapse to a first platinum-based therapy are performance status (for $90 \%$ ), comorbidities

Table 4 Preferred choices of physicians for first systemic chemotherapy, in patients eligible for cisplatin

\begin{tabular}{ll}
\hline Usual physician chemotherapy regimen for 1st & Set of Physicians \\
systemic anti-cancer therapy in patients eligible & $N=51$ \\
to cisplatin & \\
\hline As neoadjuvant or adjuvant chemotherapy ${ }^{a}$ & - \\
Missing & $3(5.9 \%)$ \\
MVAC & $1(2.0 \%)$ \\
HD-MVAC & $42(82.4 \%)$ \\
GEM-cisplatin & $3(5.9 \%)$ \\
GEM-cisplatin or (HD)-MVAC & $3(5.9 \%)$ \\
Other & \\
As palliative first-line chemotherapy & \\
Missing & - \\
MVAC & $2(3.9 \%)$ \\
HD-MVAC & - \\
GEM-cisplatin & $46(90.2 \%)$ \\
GEM-cisplatin or (HD)-MVAC & $2(3.9 \%)$ \\
\hline Other & $1(2.0 \%)$ \\
\hline
\end{tabular}

${ }^{\mathrm{a}}$ One physician ticked two answers 
Table 5 Preferred choices of physicians for first systemic chemotherapy, in patients not eligible for cisplatin

\begin{tabular}{|c|c|}
\hline $\begin{array}{l}\text { Usual physician chemotherapy regimen for } 1 \text { st line } \\
\text { anticancer systemic therapy in patients ineligible to } \\
\text { receive cisplatin }\end{array}$ & $\begin{array}{l}\text { Set of Physicians } \\
N=51\end{array}$ \\
\hline \multicolumn{2}{|l|}{ As neoadjuvant or adjuvant chemotherapy } \\
\hline Missing & - \\
\hline Single agent & - \\
\hline Chemotherapy doublet & $43(84.3 \%)$ \\
\hline Gemcitabine-carboplatin & $40(78.4 \%)$ \\
\hline Paclitaxel-carboplatin & $1(2.0 \%)$ \\
\hline Docetaxel-carboplatin & $1(2.0 \%)$ \\
\hline Gemcitabine-Paclitaxel & $1(2.0 \%)$ \\
\hline Other & $1(2.0 \%)$ \\
\hline None & $7(13.7 \%)$ \\
\hline \multicolumn{2}{|l|}{ As palliative first-line chemotherapy } \\
\hline Missing & - \\
\hline Single agent & $2(3.9 \%)$ \\
\hline Gemcitabine & $2(3.9 \%)$ \\
\hline Carboplatin (carboplatin) & - \\
\hline Chemotherapy doublet & $49(96.1 \%)$ \\
\hline Gemcitabine-carboplatin & $44(86.3 \%)$ \\
\hline Paclitaxel-carboplatin & $2(3.9 \%)$ \\
\hline Docetaxel-carboplatin & $1(2.0 \%)$ \\
\hline Gemcitabine-Paclitaxel & $1(2.0 \%)$ \\
\hline Other & 1 (2.0\%) \\
\hline
\end{tabular}

(for $55 \%$ ), response to prior chemotherapy (for $43 \%$ ), renal impairment (for $35 \%$ ) and progression-free interval after prior chemotherapy (for $31 \%$ ). European guidelines, patients/families requests and drug access also impact choices but for only 14, 10 and $8 \%$ of the clinicians, respectively.

Best supportive care is not considered in patients with PS $0-1$ but only as possible option by $26 \%$ of physicians in case of $\mathrm{PS} \geq 2$ without associated renal impairment and by $45 \%$ in case of combined adverse conditions. A vast majority of physicians consider in theory a singleagent therapy in post-platinum setting whatever the PS is (72-82 \% of cases, except for patients having combined PS $\geq 2$ and impaired renal function for whom physicians balance treatment decision with best supportive care $-51-45 \%)$. Only in patients with PS 0 and normal renal function, a doublet is considered by $31 \%$ of physicians, with no standard regimen but gemcitabinecisplatin in more than a half of them.

Vinflunine is the most frequent treatment option in patients with PS 0 or 1 independently of renal function (34-38 physicians out of the set of $51: 67-75 \%$ ), but is rarely perceived as a possible treatment in case of PS 2 $(<8 \%)$. The main reasons claimed by physicians for using vinflunine (Table 6) are phase 3 study evidence (67\%), safety profile (41\%), survival benefit (29\%) and vinflunine European approval (26\%).

The second most frequent option is paclitaxel single agent: $22-31 \%$ of physicians, regardless of PS. Gemcitabine single agent is considered mainly in patients with PS $\geq 2$ but only by $4-12 \%$ of physicians in patients with PS $0-1$.

\section{Discussion}

This observational study analyzes the clinical practice in four European countries, reporting disease management of advanced UC. It describes the proportion and main characteristics of patients receiving a second systemic anticancer treatment without the patient selection biases related to drug clinical trials where patients are usually included with good PS and few comorbidities. It is the first survey assessing European routine medical practices in advanced stages of UC previously treated with a platinum-based chemotherapy. Two retrospective epidemiological studies were previously communicated as abstracts. One assessed the type of platinum treatment given in 298 patients with stage IV disease [14]. The second retrospective data collection was conducted in selected centers with the aim of assessing prognostic factors of OS [15]. None provided such detailed information on both first-line, subsequent treatments and patients characteristics in daily practice. This is of interest considering the current gaps in clinical guidelines, in particular for the management of patients with ECOG

Table 6 Reason(s) for choosing vinflunine for management of a patient following progression/relapse to an initial platinum-based chemotherapy

Reason(s) for choosing vinflunine for management of a patient after progression/relapse to an initial platinum-based chemotherapy, $n=51$ physicians ( 0 up to a maximum of 3 reasons could be given)

\begin{tabular}{ll}
\hline Phase III evidence & $34(66.7 \%)$ \\
Safety profile & $21(41.2 \%)$ \\
Survival benefit & $15(29.4 \%)$ \\
Drug approval & $13(25.5 \%)$ \\
Guidelines & $12(23.5 \%)$ \\
Progression free survival & $11(21.6 \%)$ \\
Convenience of administration & $9(17.6 \%)$ \\
Good prior experience & $6(11.8 \%)$ \\
Best efficacy expectations & $5(9.8 \%)$ \\
Symptoms control & $4(7.8 \%)$ \\
Quality of life & $3(5.9 \%)$ \\
Simple scheme & $3(5.9 \%)$ \\
Handable schedule & $2(3.9 \%)$ \\
Disease stabilization rate & $1(2.0 \%)$ \\
Patient/family request/other reason & -
\end{tabular}


PS $\geq 2$ or with comorbidities. In addition, there is no strong phase III scientific evidence supporting the few combination therapy options that are used in practice while there are no recommendations based on recently established prognostic factors. As a consequence, practices vary.

Three out of the four chosen countries for this study (France, Italy and Spain) are among the 5 major countries for incidence and mortality from bladder cancer in the European Union, the others being Germany and the United Kingdom [3]. In order to have centers representative of actual care of advanced UC, the number of centers contacted per country was proportional to the published country bladder cancer-related mortality.

The proportion of recruited patients closely mirrored the incidence and mortality of bladder cancer in the four participating countries [3] with slight variations: Austrian patients number was above expectations and French patients were less represented.

Possible selection biases have been limited through the inclusion of all consecutive patients in each center, over a maximum time corresponding to the study duration. However it is possible that patients in very poor health conditions, not able to attend an oncologic/urologic visit, were not included in the study.

This study provides important insights on the type of UC patients who receive platinum treatments in Europe. A majority of patients (63\%) received a first platinumbased chemotherapy regimen as palliative treatment in the advanced or metastatic stage.

At the time of first systemic chemotherapy decision, $65 \%$ of the patients were theoretically fit to receive cisplatin but only $56 \%$ of them received a cisplatin-based therapy. The contra-indications to cisplatin treatment are well-known but their respective frequencies in this population of patients have never been reported. In this survey, it was observed that $70 \%$ of cisplatin-unfit patients had a single adverse condition for cisplatin use, either renal impairment (58 \%) or a PS $\geq 2$ (12\%), while hearing impairment was considered as single or combined reason in only $5 \%$.

The observed response rate in the survey (45\%) mirrors the expected response rates of $46 \%$ with the MVAC regimen and $49 \%$ with the gemcitabine-cisplatin regimen [16] but is quite important considering the rate of patients who did not receive a cisplatin-based regimen (43\%).

In the picture taken at registration, $80 \%$ of patients receive a second anticancer systemic treatment. The post-platinum therapy was most often a single agent after chemotherapy administered in the advanced/metastatic setting, and preferably a cytotoxic combination after a neoadjuvant or adjuvant chemotherapy regimen. PS and prior response to chemotherapy were the main parameters that influenced treatment decisions (both
$>50 \%)$ after a platinum-based therapy. The other published second-line prognosis factors (hemoglobinemia, liver metastasis) [13] were considered as impacting the treatment choice in less than $7 \%$ of cases. When considering the univariate and multivariate analyses testing the association between patient characteristics and the decision of subsequent single agent or polychemotherapy regimen, the strongest association was found with results achieved with the first treatment (objective response and time to progression). Age $(<$ or $\geq 75)$ did not impact on the choice of treating patients with singleagent or combination. Surprisingly, PS did not appear as an influencing factor; this may be due to the limited number of patients with $\mathrm{PS} \geq 2$ and/or to the fact that most patients treated by combination therapy or by vinflunine are PS 0 or 1.

The most frequent chemotherapy regimen after platinum was single agent vinflunine ( $42 \%$ of all second anticancer systemic treatments). Taxanes (mainly paclitaxel) are still used as single agent but represent only $13 \%$ of post-platinum chemotherapy treatments.

As of today, and outside of clinical trials, single agent therapy remains a standard in second-line treatment; actually chemotherapy doublets did not demonstrate extended survival rates even though they had shown higher response rates in phase II studies [17]. Regimens varied widely in cases where a combination therapy was administered in post-platinum setting, carboplatin being used quite often.

The real-life conditions of this study show that the health status and prognosis of patients seen in routine practice, are not worse than those of patients participating to the pivotal phase III vinflunine trial [18], in which PS 2 patients were excluded. Patients with PS 0-1- $\geq 2$ were $36 \%-47 \%-17 \%$ here vs $28 \%-72 \%-0 \%$ in the phase III trial. Renal impairment (as defined by a creatinine clearance $<60 \mathrm{~mL} / \mathrm{min}$ ) was $44 \%$ vs $47 \%$. The population in this survey showed relatively low visceral metastases involvement, with only $13 \%$ patients presenting hepatic metastases (vs $29 \%$ in the pivotal phase III). Another adverse prognosis factor, hemoglobinemia < $10 \mathrm{~g} / \mathrm{dL}$ was reported in only $16 \%$ of patients in this study as compared to $86 \%$ in the phase III trial.

After platinum-based chemotherapy failure, vinflunine is the only chemotherapeutic agent approved in Europe. The approval was based on a randomized phase III trial investigating vinflunine plus best supportive care (BSC) versus BSC alone [18]. The results showed clinical benefit with a favorable safety profile and a survival benefit in favor of vinflunine, which was statistically significant in the eligible patient population, with a $22 \%$ reduction of the risk of death being achieved [19].

Recently, different prospective or retrospective studies of vinflunine have been published, on the basis of German, 
Spanish, Greek and British series of patients receiving a second-line treatment or more [20-23]. In these studies patients with PS 2 represented 8-23\% and liver metastasis was reported in $17-29 \%$ of patients. Interesting response rates were obtained, comprised between 13 and $29 \%$ and overall survival was between 7.7 and 11.9 months.

Second-line response rates obtained with taxanes, ifosfamide, topotecan, pemetrexed and different tyrosine kinase inhibitors have ranged between 0 and $28 \%$ in small phase II trials [24].

Gemcitabine displayed also interesting response rates in second-line treatment, but most patients already receive this drug in first-line [25]. Paclitaxel/gemcitabine studies have shown increased response rates, but no randomized phase III trial with an adequate comparator arm has been conducted to assess the true value and OS benefit of this second-line combination $[5,26]$.

Checkpoint inhibitors, e.g. targeting the PD-1/PD-L1 axis, hold promising potential with good tolerability in advanced UC [27]. Atezolizumab was recently approved in the United States by the Food and Drug Administration [28] on the basis of a large phase II study involving 310 patients with UC progressing following platinum treatment [29]. This approval was granted in a country where there was no approved drug in the second-line setting. In Europe, no checkpoint inhibitors have been approved yet for the treatment of UC. Combining chemotherapies with immunotherapies may provide valuable options with improved response rates and tolerable toxicity.

\section{Conclusion}

This study conducted in four European countries reflects daily practice in the treatment of patients with urothelial carcinoma eligible for a first platinum-based chemotherapy either in adjuvant/neoadjuvant or in advanced/ metastatic setting. It fills a knowledge gap on the characteristics of UC patients treated with platinum agents and on the reasons and modalities of further treatments. Cisplatin was used in $56 \%$ of patients. Cisplatin-ineligibility appeared mainly due to renal dysfunction $(68 \%)$ and PS $\geq 2$ (21\%).

A second chemotherapy regimen was administered in $80 \%$ of patients. Most often this was a single agent following an initial systemic chemotherapy administered in the first-line advanced setting (70\% of patients); after a neoadjuvant or adjuvant chemotherapy, the preference was for a cytotoxic combination (60\% of patients). PS and prior response to chemotherapy were the main parameters that influenced disease management. The most frequent second systemic anticancer therapy was single agent vinflunine ( $42 \%$ of all subsequent systemic therapies), the main reasons evoked by physicians being survival benefit, safety and phase III evidence.

\section{Abbreviations}

ASCO: American Society of Clinical Oncology; BSC: Best supportive care;

$\mathrm{Cl}$ : Confidence interval; EAU: European Association of Urology; ECOG: Eastern Cooperative Oncology Group; ESMO: European Society of Medical Oncology; GEM: Gemcitabine; HD-MVAC: High-dose-intensity methotrexate, vinblastine, doxorubicin and cisplatin; HR: Hazard ratio; MVAC: Methotrexate, vinblastine, doxorubicin and cisplatin; OS: Overall survival; PD-1: Programmed death receptor 1; PD-L1: Programmed death-ligand 1; PS: Performance status; UC: Urothelial carcinoma

\section{Acknowledgements}

The authors thank Dr R. Defrance for medical writing assistance

\section{Funding}

Institut de Recherche Pierre Fabre provided funding to ensure data collection, data management, descriptive statistical analyses and medical writing.

\section{Availability of data and materials}

Study report is fully available upon request.

\section{Authors' contributions}

$\mathrm{NH}$ contributed to conception and design, acquisition and interpretation of data, and drafting the manuscript. CL and JB contributed to conception and design, analysis and interpretation of data, and drafting the manuscript. $G \mathrm{~L}$, HSP, UB, DS, RT, LB, FM, CT, LL, NL, AG, GT, XGDM contributed to acquisition and interpretation of data, and revised the manuscript for scientific content. All authors have read and approved the manuscript.

\section{Competing interests}

N. Houédé received investigator honorarium from Pierre Fabre Company for the submitted work

C. Lucas and J. Bielle are Pierre Fabre employees.

G. Locker, H. Soto Parra, U. Basso, D. Spaeth, R. Tambaro, L. Basterretxea, F.

Morelli, C. Theodore, L. Lusuardi, N. Lainez, A. Guillot, G. Tonini, X. Garcia Del

Muro have no competing interests for the current work.

\section{Consent for publication}

Not applicable.

\section{Ethics approval and consent to participate}

All patients signed a specific informed consent if requested or at least received a detailed written information. In compliance with each participating country regulations, the study was approved by national authorities as a non-interventional study and assessed by ethics review boards of each participating institution, wherever applicable.

France: Approval from the « Comité Consultatif sur le Traitement de I'Information en matière de Recherche dans le domaine de la Santé (CCTIRS) » granted on the 27 February 2013. Approval from the «Commission Nationale de l'Informatique et des Libertés (CNIL) » granted on the 10 April 2013. Spain: Approval from the Ethics Committee of "Hospital Universitari de Bellvitge - Catalunya" on the 10 January 2013.

Austria: Approval from the Ethics Committee "Ethikkomission des Landes Oberösterreich" on the 21 January 2013.

Italy: Approval from the Ethics Committee of "Azienda Ospedaliero-universitaria Policlinico Vittorio Emanuele - Catania" on the 22 January 2013.

\section{Author details}

'Institut de Cancérologie du Gard - CHU Caremeau, 30029 Nîmes, Cedex 9, France. ${ }^{2}$ Department of Internal Medicine I, Währinger Gürtel.18-20, 1090 Vienne, Austria. ${ }^{3}$ Institut de Recherche Pierre Fabre, 45 place Abel Gance, 92100 Boulogne-Billancourt, France. ${ }^{4}$ Oncologia Medica, P.O Gaspare Rodolico, Via Santa Sofia 78, 95123 Catania, Italy. ${ }^{5}$ Istituto Oncologico Veneto IOV-IRCCS, Dipartmento di Oncologia Clinica e Sperimentale, Oncologia Medica 1, via Gattamelata 64, 35128 Padova, Italy. ${ }^{6}$ Centre d'Oncologie de Gentilly, 2 rue Marie Marvingt, 54100 Nancy, France. ${ }^{7}$ Istituto Nazionale Tumori IRCCS Fondazione Pascale, Via Mariano Semmola, 80131 Napoli, Italy. ${ }^{8}$ Hospital Universitario Donostia, Begiristain Doktorea Pasealekua 117-20080, Donostia, Gipuzkoa - San Sebastián, Spain. ${ }^{9}$ Fondazione Casa Sollievo della Sofferenza Oncologia, Viale Cappuccini 1, San Giovanni Rotondo, Foggia, Italy. ${ }^{10}$ Hopital Foch, 40 rue Worth, 92150 Suresnes, France. ${ }^{11}$ Reparto di 
Urologia - Ospedale di Bressanone, Via Dante 51, 39042 Bressanone, Italy. ${ }^{12}$ Hospital de Navarra - Virgen del Camino, Oncología Médica, Calle de Irunlarrea, 4 planta baja, 31008 Pamplona, Spain. ${ }^{13}$ Institut de cancérologie de la Loire, 108 bis avenue Albert Raimond, 42271 Saint Priest en Jarez, Cedex, France. ${ }^{14}$ Policlinico Universitario Campus Bio-medico Oncologia Medica, Via Alvaro del Portillo 200, 00128 Roma, Italy. ${ }^{15}$ ICO L'Hospitalet, Avinguda Granvia, 199-203, 08907 L'Hospitalet de Llobregat, Barcelona, Spain.

Received: 10 May 2016 Accepted: 14 September 2016

Published online: 23 September 2016

\section{References}

1. Pasin E, Josephson DY, Mitra AP, Cote RJ, Stein JP. Superficial bladder cancer: an update on etiology, molecular development, classification, and natural history. Rev Urol. 2008;10:31-43.

2. Muscle-invasive and metastatic bladder cancer - EAU guidelines 2015 [Internet]. http://uroweb.org/wp-content/uploads/07-Muscle-Invasive-BC_LR. pdf. Accessed 11 July 2016

3. Globocan. Table by populations (Incidence/Mortality) [Internet]. 2012. http:// globocan.iarc.fr/Pages/summary_table_site_sel.aspx. Accessed 11 July 2016

4. Rosenberg JE, Carroll PR, Small EJ. Update on chemotherapy for advanced bladder cancer. J Urol. 2005;174:14-20.

5. Sternberg CN, Vogelzang NJ. Gemcitabine, paclitaxel, pemetrexed and other newer agents in urothelial and kidney cancers. Crit Rev Oncol Hematol. 2003;46 Suppl:S105-15.

6. von der Maase H, Sengelov L, Roberts JT, Ricci S, Dogliotti L, Oliver T, et al. Long-term survival results of a randomized trial comparing gemcitabine plus cisplatin, with methotrexate, vinblastine, doxorubicin, plus cisplatin in patients with bladder cancer. J Clin Oncol. 2005;23:4602-8.

7. Bellmunt J, Petrylak DP. New therapeutic challenges in advanced bladder cancer. Semin Oncol. 2012;39:598-607.

8. Bellmunt J, Orsola A, Leow JJ, Wiegel T, De Santis M, Horwich A, et al. Bladder cancer: ESMO Practice Guidelines for diagnosis, treatment and follow-up. Ann Oncol. 2014;25 Suppl 3:iii40-8.

9. Dash A, Galsky MD, Vickers AJ, Serio AM, Koppie TM, Dalbagni G, et al. Impact of renal impairment on eligibility for adjuvant cisplatin-based chemotherapy in patients with urothelial carcinoma of the bladder. Cancer. 2006;107:506-13.

10. Milowsky MI, Rumble RB, Booth CM, Gilligan T, Eapen LJ, Hauke RJ, et al. Guideline on Muscle-Invasive and Metastatic Bladder Cancer (European Association of Urology Guideline): American Society of Clinical Oncology Clinical Practice Guideline Endorsement. J Clin Oncol. 2016:34:1945-52.

11. Leow JJ, Martin-Doyle W, Rajagopal PS, Patel CG, Anderson EM, Rothman AT, et al. Adjuvant chemotherapy for invasive bladder cancer: a 2013 updated systematic review and meta-analysis of randomized trials. Eur Urol. 2014;66:42-54.

12. Galsky MD, Stensland KD, Moshier E, Sfakianos JP, McBride RB, Tsao C-K, et al. Effectiveness of Adjuvant Chemotherapy for Locally Advanced Bladder Cancer. J Clin Oncol. 2016;34:825-32.

13. Bellmunt J, Choueiri TK, Fougeray R, Schutz FAB, Salhi $Y$, Winquist $E$, et al. Prognostic factors in patients with advanced transitional cell carcinoma of the urothelial tract experiencing treatment failure with platinum-containing regimens. J Clin Oncol. 2010;28:1850-5.

14. Sonpavde G, Watson D, Tourtellott M, Cowey CL, Hellerstedt B, Hutson TE, et al. Administration of cisplatin-based chemotherapy for advanced Urothelial carcinoma in the community. Clin Genitourin Cancer. 2012;10:1-5.

15. Galsky MD. Treatment patterns and outcomes in "real world" patients (pts) with metastatic urothelial cancer (UC). J Clin Oncol. http://meetinglibrary. asco.org/content/110719-132. Accessed 11 July 2016.

16. von der Maase H, Hansen SW, Roberts JT, Dogliotti L, Oliver T, Moore MJ, et al. Gemcitabine and cisplatin versus methotrexate, vinblastine, doxorubicin, and cisplatin in advanced or metastatic bladder cancer: results of a large, randomized, multinational, multicenter, phase III study. J Clin Oncol. 2000;18:3068-77.

17. Raggi D, Miceli R, Sonpavde G, Giannatempo P, Mariani L, Galsky MD, et al. Second-line single-agent versus doublet chemotherapy as salvage therapy for metastatic urothelial cancer: a systematic review and meta-analysis. Ann Oncol. 2016:27:49-61.

18. Bellmunt J, Theodore C, Demkov T, Komyakov B, Sengelov L, Daugaard G, et al. Phase III trial of vinflunine plus best supportive care compared with best supportive care alone after a platinum-containing regimen in patients with advanced transitional cell carcinoma of the Urothelial tract. J Clin Oncol. 2009:27:4454-61.

19. Bellmunt J, Fougeray R, Rosenberg JE, von der Maase H, Schutz FA, Salhi Y, et al. Long-term survival results of a randomized phase III trial of vinflunine plus best supportive care versus best supportive care alone in advanced urothelial carcinoma patients after failure of platinum-based chemotherapy. Ann Oncol. 2013;24:1466-72.

20. Retz M, de Geeter P, Goebell PJ, Matz U, de Schultz W, Hegele A. Vinflunine in routine clinical practice for the treatment of advanced or metastatic urothelial cell carcinoma - data from a prospective, multicenter experience. BMC Cancer. 2015:15:455.

21. Castellano D, Puente J, de Velasco G, Chirivella I, López-Criado P, Mohedano $\mathrm{N}$, et al. Safety and effectiveness of vinflunine in patients with metastatic transitional cell carcinoma of the urothelial tract after failure of one platinum-based systemic therapy in clinical practice. BMC Cancer. 2014;14: 779.

22. Pistamaltzian N, Tzannis K, Pissanidou V, Peroukidis S, Milaki G, Karavasilis V, et al. Treatment of relapsed urothelial bladder cancer with vinflunine: realworld evidence by the Hellenic Genitourinary Cancer Group. Anticancer Drugs. 2016;27:48-53

23. VICTOR. Vinflunine (Vin) in advanced metastatic transitional cell carcinoma of the urothelium (TCCU) - A retrospective analysis of use of Vin in multicenter, real life setting as second-line chemotherapy (ChT) through free-of charge-programme (FOCP) for patients (pts) in the UK. | 2015. Genitourinary Cancers Symposium | Abstracts | Meeting Library [Internet]. http://meetinglibrary.asco.org/content/141508-159. Accessed 11 July 2016.

24. Yafi FA, North S, Kassouf W. First- and second-line therapy for metastatic urothelial carcinoma of the bladder. Curr Oncol Tor Ont. 2011:18:e25-34.

25. von der Maase H. Gemcitabine in transitional cell carcinoma of the urothelium. Expert Rev Anticancer Ther. 2003;3:11-9.

26. Albers P, Park S-I, Niegisch G, Fechner G, Steiner U, Lehmann J, et al. Randomized phase III trial of 2nd line gemcitabine and paclitaxel chemotherapy in patients with advanced bladder cancer: short-term versus prolonged treatment [German Association of Urological Oncology (AUO) trial AB 20/99]. Ann Oncol. 2011:22:288-94.

27. Powles T, Eder JP, Fine GD, Braiteh FS, Loriot Y, Cruz C, et al. MPDL3280A (anti-PD-L1) treatment leads to clinical activity in metastatic bladder cancer. Nature. 2014;515:558-62.

28. Press Announcements - FDA approves new, targeted treatment for bladder cancer [Internet]. http://www.fda.gov/NewsEvents/Newsroom/ PressAnnouncements/ucm501762.htm. Accessed 11 July 2016.

29. Rosenberg JE, Hoffman-Censits J, Powles T, van der Heijden MS, Balar AV, Necchi A, et al. Atezolizumab in patients with locally advanced and metastatic urothelial carcinoma who have progressed following treatment with platinum-based chemotherapy: a single-arm, multicentre, phase 2 trial. Lancet. 2016:387:1909-20.

\section{Submit your next manuscript to BioMed Central and we will help you at every step:}

- We accept pre-submission inquiries

- Our selector tool helps you to find the most relevant journal

- We provide round the clock customer support

- Convenient online submission

- Thorough peer review

- Inclusion in PubMed and all major indexing services

- Maximum visibility for your research

Submit your manuscript at www.biomedcentral.com/submit
) Biomed Central 